\title{
APPLYING ANALYTICAL HIERARCHY PROCESS TO SUPPLIER SELECTION AND EVALUATION IN THE HOSPITALITY INDUSTRY: A MULTIOBJECTIVE APPROACH
}

\author{
Kaie-Chin CHUNG \\ Department of Hospitality Management, Taoyuan Innovation Institute of Technology, No. 414, \\ Sec. 3, Jhongshan E. Rd., Jhongli Taoyuan 32091, Taiwan, R.O.C. \\ E-mail:david@tiit.edu.tw
}

\begin{abstract}
The present study's primary objective is to identify contributing factors in selecting and evaluating a seafood supplier within the Taiwanese hospitality industry. It illustrates the application of a multicriteria decision-making process to supplier selection within a service setting where it is less common than in a manufacturing context. To implement the study, a survey instrument was created and submitted to Taiwanese hospitality firms, namely hotels and restaurants, to identify contributing factors in the selection of a seafood supplier within six initial areas concerning food hygiene, staff training, crisis management, information technology, competitive ability, and logistics and quality assurance. The analytic hierarchical process (AHP) was then applied to the survey results, and the first- and second-level hierarchical factors were rigorously identified and ranked. These can be regarded as useful benchmarks in identifying and ranking the selection and evaluation of a food supplier within the industry. The present study enhances the understanding of supplier selection in the hospitality industry and provides insights which hospitality firms can apply in managing their supply chains. The managerial and research implications of these findings are discussed.
\end{abstract}

Keywords: analytical hierarchy process, supply chain management, supplier selection, hospitality industry

\section{INTRODUCTION}

In today's competitive business environment, effective supplier selection and evaluation processes have been shown to play a pivotal role in enhancing a firm's performance, whether in the manufacturing or the service industry, as the cost and quality of goods and services sold relate directly to the cost and quality of goods and services purchased (Sevkli et al. 2008). Competitive advantages re- 
lated with supply chain management (SCM) philosophy could be accomplished by strategic partnership with suppliers and service providers. The success of a supply chain is highly associated with the selection of good suppliers. Simply seeking for vendors offering the lowest prices is not "efficient sourcing" any more. Multiple criteria need to be taken into account when selecting suppliers (Ng 2008). The supplier selection problem has received considerable attention in academic research and literature.

Therefore, the supplier selection problem has become one of the most important components in supply chain management (SCM). Supplier selection is a multiple-attribute decision-making process in which decision makers express their preferences on alternative suppliers or on supplier attributes, which are then used to rank and select suppliers (Li et al. 1997). Supplier selection is a multipleattribute decision-making (MADM) problem. The key purpose of the supplier selection is to minimize buying risk, maximize value to the buyer, and develop close, and long-term relationships between buyers and suppliers, all of which are effective in assisting the firm optimize its cost of goods and services. The supplier selection within the supply chain system may be a group decision based on a number of criteria selected from multiple possible ones employed in previous and present such decision models (Chen et al. 2006).

Conventionally, vendors are selected from among many suppliers based on their abilities to meet the firm's quality requirements, delivery schedule, and pricing objectives (Sevkli et al. 2008). The main objective in this approach is to obtain the lowest possible price in order to reduce the cost of the product or service so as to enhance the firm competitiveness, while at the same time maintaining acceptable quality and reliability standards. In the modern business world, many firms prefer a strategy involving relatively few suppliers (Chandra and Kumar 2000), seeking long-term relationships and the collaboration of a few dedicated suppliers rather than many less dedicated relationships. Using fewer suppliers can lead to value for the buyer and produce lower transaction in conjunction with lower manufacturing costs. Cooperation between buyer and supplier consists of specified work-flow, sharing information through electronic data interchange and the Internet, joint planning, and other mechanisms that permit it to perform a justin-time (JIT) system and practice total quality management (TQM) (Spekman et al. 1998). By implementing advanced concepts in materials management, quality management, logistics, and achievement of JIT objectives, a firm then works with specialized suppliers to produce a product having acceptable quality. As can be seen, the process of the supplier selection and evaluation is a multi-objective decision composed of a number of tangible and intangible determinants in a hierarchical manner. A variety of factors adopted as criteria for supplier selection contain price, delivery performance, reputation in the industry, size of enterprise, 
geographical location, quality, environmental compliance, capacity, services, lead-time, packaging, transportation storage, and product development (Kahraman et al. 2003; Sevkli et al. 2008; Kar and Pani 2014).

The majority of the research methods proposed to solve the supplier selection problem have been within a manufacturing setting; a relatively small number have been conducted to explore the rationale in a service setting, such as the hospitality setting. Thus, the existing empirical literature in the manufacturing industry provides effective paradigms for developing and utilizing similar constructs and proposing alternative structures of associations among the variables that are selected for the present study to focus on the delivery of service within the hospitality industry.

Moreover, an increasing number of hospitality service providers, i.e., hotels and restaurants, have begun to collaborate with suppliers to procure drinks, food, culinary materials, and various types of logistical support to ensure efficient delivery of daily hospitality services (Smith and Xiao 2008; Fantazy et al. 2010; Pullman and Rodgers 2010). These have engaged in extensive coordination with suppliers and have even integrated them into their operations, thus employing cooperation with business partners in business activities to provide excellent service (Shi and Liao 2013). Hence, management and selection of suppliers by hospitality firms have become emerging and essential issues.

The limitations of existing related literature on the supplier selection and evaluation in the setting of the hospitality industry, has inspired the conduct of this research project in Taiwan where this type of researches conducted herein are scant at present. This investigation will focus on analytic hierarchy process (AHP) with the multiple criteria decision making (MCDM) theory proposed by Saaty (1980) as an effective and efficient technology for performance evaluation of the supply chain within this industry.

This article focuses on the need for evaluating supplier selection based on performance and seeks to develop a general framework to assess the specific service supply chain requirements within the hospitality industry. In particular, the present study hopes to respond to certain important issues of supplier selection and enrich existing theory and practices with the context of the hospitality industry.

By applying the analytic hierarchy process (AHP) approach, the present study has endeavored to investigate the contributing factors for strategic supplier selection and evaluation in a hospitality setting situated in Taiwan. As an island nation, Taiwan relies heavily on seafood as a food source, and seafood occupies a central role in the national cuisine. As it is a relatively small island, Taiwan is significantly dependent on outside suppliers for variety of food stuffs. Seafood produce's perishability leads to an emphasis on hygiene in product handling at 
all points throughout the supply chain and on logistics in getting the product to the hotels and restaurants which purchase it in a timely manner. Therefore, the appropriate selection of a variety of fresh seafood in sufficient quantity and of acceptable quality is essential to the development of the Taiwanese hospitality industry.

This paper will be developed in six sections. Section 2 provides a comprehensive review of the literature presented as the conceptual foundation for the study. Section 3 explains the methodology for the framework of the study. Section 4 presents the study results, and Section 5 discusses the conclusions that can be drawn from the research. Ultimately, the paper is a discourse on the theoretical contributions and the managerial insights that have emerged out of this research project.

\section{BACKGROUND LITERATURE}

\subsection{Supply chain management}

Supply chain management (SCM), which can be viewed as the flow of materials from suppliers through manufacturers or service providers and then on to the end consumer, is an integrated approach that begins with planning and involves control of materials, logistics, services, as well as information (Fantazy et. al. 2010). It represents a major change in modern business management practices. Moreover, apart from the manufacturing setting, it is gaining increasing interest among researchers and practitioners in the service industry. Its increasing importance is due to the profound impact suppliers have on costs incurred by purchaser firms within the supply chain and the quality of these firms' end products (Zhang et al. 2013). Moreover, suppliers have been known to play an important role in the support of a firm's competitive strategy. Competitive advantages can be achieved by the establishment of a sound supply chain system. The success of a supply chain system is highly dependent on the selection of good suppliers. While SCM has gained attention both in the practical and academic setting, the concept of supplier selection - one of SCM's most important components - has also been expanding.

Supplier selection is a process by which suppliers are reviewed, evaluated, and chosen to become a part of the organization's supply chain (Saen 2009). Organizations in which purchasing has a significant impact on revenues require a global edge in the wake of increasing competition (Fantazy et al. 2010). For such organizations, a comprehensive approach to decision-making is highly desirable. It a multiple objective decision making (MODM) problem. The decision makers 
always show their preferences on alternatives or attributes of suppliers that can be used to help rank and select the suppliers. The preference and selection of suppliers belongs to decision makers' subjective judgments. Thus, the problem of supplier selection has become a challenging process ( $\mathrm{Li}$ et al. 2007). A large number of researches on supplier selection have been conducted over the past decades employing multi-criteria decision-making methods.

In the management of the service supply chain, the performance of potential suppliers is justified based on a number of criteria (Cho et. al. 2012). Service suppliers require more close cooperation than those manufacturing ones as they carry out various activities in a whole service process to impress customers (Feng et. al. 2011). Limited literatures have been conducted on the selection and evaluation of suppliers in the service supply setting, although a variety of theories and practices explored in the manufacturing supply chains provide useful information for researchers (Kim and Ellegaard 2011). Thus, to assess suppliers' performance in the service supply system with quantitative data is necessary. The scope of quantitative information encompasses delivery lead time, service quality, risk sharing initiatives, cost saving initiatives, as well as pricing. Tactical level measures are composed of the utilization of service facilities, equipment and staff, the delivery efficiency of supporting activities, booking in procedures, cash flow, volume and specification flexibility and quality assurance methodology. Operational level measures include ability to perform the task of daily technical representation, adherence to a committed schedule, and ability to avoid complaints of delivery.

The results of these studies provide a basis for the constructs and variables of the present study set within the service industry, and lay the foundation for the investigation of the present study. Supplier selection methods reported in the extant literature include cluster analysis, case-based reasoning systems, statistical models, decision support systems, data envelopment analysis, analytic hierarchy process (AHP), total cost of ownership models, activity-based costing, artificial intelligence, and mathematical programming ( $\mathrm{Li}$ et al. 1997). These methods offer systematic approaches for buyers to estimate and score suppliers with multicriteria. However, they are not easy to be designed and implemented. Methods that are based on multi-objective optimization require the decision makers to determine the precise values of weights of individual criteria. This is not easy to carry on, as the determination of weight is very challenging. To help decision makers define the weights, the AHP approach provides interactive comparisons for users to obtain the weights ( $\mathrm{Ng} 2008)$. It, in particular, is relatively and widely regarded as a useful decision support technique in management research for the problem of supplier selection (Sevkli et. al. 2008). 


\subsection{Analytical hierarchy process}

Analytical hierarchy process (AHP), a decision-making method developed for prioritizing alternatives when multiple criteria must be considered, allows the decision maker to structure complex problems in the form of hierarchies, or sets of integrated levels (Cho et al. 2012). This research, thus, guided by the wealth of literature evolved by related industries, seeks to analyze the complexity of the multi-criteria and propose the possible reconfiguration of this into a hierarchy of multiple levels with the goal or objective positioned at the highest, the criteria and sub-criteria occupying the middle, and the alternatives at the base (Saaty 1980; Crowe et al. 1998). As a result of being easy to use and comprehend, it can incorporate qualitative and quantitative criteria simultaneously. Decision makers rank different courses of action based on their judgment concerning the relative consequence of criteria and the extent to which each alternative meets these criteria. Wide discussion attests to the technique's empirical effectiveness and theoretical validity. Thus, it is a suitable technique for ranking alternatives when a number of criteria are present in the decision-making process.

AHP is a quantitative technique that facilitates structuring a complex multiattribute problem, and provides an objective methodology for deciding which among the existing sets of solution strategies is most effective and appropriate for solving a problem (Cho et al. 2012). The procedures of the AHP involve the application of several essential steps (Isaai et al. 2011; Taliba et al. 2011). The first entails the separation of the complex problem into a hierarchical system of elements; the second step requires pairwise comparisons of elements in each hierarchy by the use of a nominal scale to stand for the comparative weights among different elements of a certain hierarchy and the eigenvector of the matrix is extracted; third, to set up a matrix, the results of comparison are quantified; fourth, to evaluate the consistency ratio of the comparative matrix and decide to accept or reject the information, the eigenvalue is utilized. To generate significant information regarding the preferences of the decision maker, pairwise comparison is then applied.

As it uses a ratio scale for human judgments, alternatives' weights stand for the consequence of the criteria in goal attainment (Maggie and Tummala 2001). It also accommodates uncertainties and subjective information and allows the application of experience, insight, and intuition in a logical manner. The ultimate rationale of AHP is to empower decision makers to rank and order the alternate solution strategies on their final score and choose the best. One of the key advantages of AHP is that it is relatively easy to reconfigure a number of criteria. Besides, it is able to rationalize both qualitative and quantitative data accurately. An analysis of the different applications of AHP found in the existing literature 
shows that priority and ranking are applications widely used in different areas (Chin et al. 2002; Vaidya and Kumar 2006) and are therefore applied in the present study.

AHP has been used for supplier selection and evaluation primarily in a manufacturing setting in order to rank suppliers concerning relative importance of the criteria of selection and the suitability of supplier with respect to these criteria. Many believe that this technology, thus, is the best alternative to measure the performance of the service supply chain (Cho et al. 2012). Thus, the present study employed AHP in a service industry setting, specifically the hospitality industry, in hopes of providing valuable insights for that specific industry and for service industries in general.

\section{RESEARCH METHODOLOGY}

To conduct the performance appraisal in a service supply chain is complicated and may vary within the service sector cutting across industries. This process involves the use of a number of criteria that are not easy to measure. On the other hand, many selection models found in existing literature focused on the performance evaluation of the service sector utilize statistical and decision theory models (Buyukozkan et al. 2011). One glaring difficulty with the performance assessment process within the service sector is the ambiguity of innovative technology and the absence of extensive scholarship to validate these technologies.

A precision-oriented method should be evolved to address this ambiguity and manage intangible variables and the multiple criteria structures found in existing technologies. MCDM (multiple criteria decision making) is an area of discourse in performance evaluation that seeks to provide workable guidelines for decision makers who are confronted with confusion in the choice of the appropriate and effective as well as efficient technology of performance evaluation given the existence of numerous and conflicting options. It is widely considered as one of the most popular MCDM methods for decision making that is extensively used in the service sector (Buyukozkan et al. 2011).

Thus, the present study's approach employed analytic hierarchical process (AHP) to identify and rank the contributing factors in selection of a seafood supplier in the context of the Taiwanese hospitality industry. A panel of ten experts drawn from academia and the hospitality industry itself were invited and provided advice throughout the entire process of selecting and refining the AHP multiple layers of factors. The Delphi method was used to elicit preliminary lists of first- and second-level factors. A survey instrument was then designed and administered to suppliers and buyers within the industry in order to validate the 
items on the initial list. Based on analysis of survey results, the initial factor lists were refined, and a final set of hierarchical factors was selected. The expert panel provided an important resource of information throughout the entire study.

Aided by the panel and published studies and using the AHP and Delphi method, an initial hierarchy of six first-level factors and some supporting second-level factors was created. To minimize bias with respect to individual factors, a factor was deleted from the hierarchy if all members of the panel believed that it should be deleted and retained if at least one panel member considered that it should be retained. Once selected, the elements of the hierarchy were incorporated in the creation of the survey instrument whose purpose was to validate and refine the initial hierarchy. In total, 235 surveys were sent out to survey respondents, who were drawn from the management of Taiwanese hotels and restaurants that are well known and appear to provide high quality service. Of the 235 surveys sent, 23 were considered invalid and so were discarded, leaving 212 valid responses. When returned, the contents of the survey were analyzed via Expert Choice 2000 software. Duncan's multiple range test was employed in testing significance of first-level factors of the hierarchy to adjust for use of multiple second-level factors. Moreover, Cronbach's $\alpha$ was calculated for each of the six first-level factors in order to test for consistency of agreement among respondents as to the factor's importance. The resulting hierarchy was then analyzed by way of Expert Choice 2000. Global numerical priorities were calculated for each first-level factor, and global and local priorities were calculated for each second-level factor. In this way, the relative importance of each factor in the process of selecting a seafood supplier was determined.

\section{RESULTS}

Selected with the help of the expert panel, the six initial first-level factors are presented in Table 1 and discussed below. The survey data gathered were analyzed to validate and further refine the preliminary hierarchy of factors. First performed was Duncan's multiple range test, which adjusts for the bias introduced by multiple comparison factors, such as the multiple second-level factors associated with a single first-level factor, in testing for the statistical significance of each. Also, calculated initially was Cronbach's $\alpha$, which measures the internal consistency of a group of data as follows: $\alpha \geq 0.9$ high; $0.7 \leq \alpha<0.9$ acceptable; $0.6 \leq \alpha<0.7 ; 0.5 \leq \alpha<0.6$ poor; and $\alpha<0.5$ no internal consistency whatsoever. For the six initial first-level factors selected, Table 1 reports the factors and the values of Cronbach's $\alpha$.

As can be seen, two of the initial six first-level factors fail to elicit any but the most minimal agreement as to their importance. These two are food hygiene and 
Table 1 . The reliability analysis

\begin{tabular}{lll}
\hline Dimension & Mean & Cronbach's $\alpha$ \\
\hline Food hygiene & 2.45 & $0.457^{\mathrm{e}}$ \\
Staff training & 2.75 & $0.563^{\mathrm{d}}$ \\
Crisis management & 3.84 & $0.836^{\mathrm{a}}$ \\
Competitive ability & 3.57 & $0.738^{\mathrm{b}}$ \\
Information technology & 3.50 & $0.705^{\mathrm{c}^{*}}$ \\
Logistics and quality assurance & 3.85 & $0.827^{\mathrm{a}}$ \\
\hline
\end{tabular}

Note: *Different superscript letters (a-e) indicating level of difference between data within the same group with a representing the least difference and e the most.

staff training, which were therefore dropped from the study. Moreover, they were felt to be subsumed under other first-level factors. For instance, staff training was felt to fall under competitive advantage, with food hygiene under logistics and quality assurance. Thus, the six first-level factors were reduced to the four shown in Table 2 below. Along with each first-level factor are shown its supporting, second-level factors, those elements believed to most strongly influence them.

Through the AHP technique, the expert team judged the relative importance of each second-level factor with respect to its corresponding first-level factor according to the AHP technique and calculated priorities among first- and secondlevel factors, which Table 2 below displays. Note that, for each first-level factor, consistency ratio (C.R.) is less than 0.1 . This ratio measures inconsistency within the decision maker's rankings and a value in excess of 0.1 warns the decision maker to re-evaluate his judgments as to relative importance among the decision criteria. C.R.s for all second-level rankings fell well below this threshold, indicating consistency in rankings. Local priorities, which measure relative weight of a factor among all peer factors (i.e., all factors at the same level on the same branch), were calculated for each first-level factor in the hierarchy, and local priorities and global priorities, which measure relative weight among all factors irrespective of level, were calculated for each second-level factor. These weights are presented for each factor in Table 2.

\section{DISCUSSION}

Among the four first-level factors in support of seafood supplier selection, logistics and quality assurance has the highest local priority (see Figure 1). Given the criticality due to product perishability within the industry, the importance awarded this factor is understandable. With very close local priorities, crisis management and information technology rank second and third, respectively, with competitive ability placing fourth. 
Table 2. The analysis results for overall assessment factors

\begin{tabular}{|c|c|c|c|c|c|}
\hline $\begin{array}{l}\text { First-level } \\
\text { factor }\end{array}$ & $\begin{array}{l}\text { Local } \\
\text { priority }\end{array}$ & $\begin{array}{l}\text { Second-level } \\
\text { factor }\end{array}$ & $\begin{array}{l}\text { Local } \\
\text { priority }\end{array}$ & $\begin{array}{l}\text { Global } \\
\text { priority }\end{array}$ & $\begin{array}{r}\text { Weight } \\
\text { ranking }\end{array}$ \\
\hline \multirow[t]{5}{*}{$\begin{array}{l}\text { Competitive } \\
\text { ability }\end{array}$} & $0.205^{\mathrm{c}^{*}}$ & $\begin{array}{l}\text { Financial management, } \\
\text { bank credit, and market } \\
\text { reputation }\end{array}$ & 0.218 & 0.047 & 12 \\
\hline & & Cost control & 0.265 & 0.057 & 9 \\
\hline & & Supply chain management & 0.228 & 0.049 & 11 \\
\hline & & Human resources & 0.200 & 0.043 & 13 \\
\hline & & $\lambda \max =.025$ & $\mathrm{CI}=0.005$ & $\mathrm{CR}=0.005$ & \\
\hline \multirow[t]{4}{*}{$\begin{array}{l}\text { Information } \\
\text { technology }\end{array}$} & $0.225^{\mathrm{b}}$ & $\begin{array}{l}\text { Application of internal } \\
\text { and external information }\end{array}$ & 0.274 & 0.060 & 8 \\
\hline & & $\begin{array}{l}\text { Application of market } \\
\text { information and evaluation } \\
\text { of market demand }\end{array}$ & 0.477 & 0.104 & 4 \\
\hline & & $\begin{array}{l}\text { E-commerce and market } \\
\text { expansion }\end{array}$ & 0.225 & 0.049 & 10 \\
\hline & & $\lambda \max =.031$ & $\mathrm{CI}=0.016$ & $\mathrm{CR}=0.028$ & \\
\hline \multirow{4}{*}{$\begin{array}{l}\text { Logistics } \\
\text { and quality } \\
\text { assurance }\end{array}$} & $0.357^{\mathrm{a}}$ & Logistics system & 0.332 & 0.117 & 1 \\
\hline & & $\begin{array}{l}\text { Certification of HACCP } \\
\text { and ISO } 22000\end{array}$ & 0.316 & 0.111 & 2 \\
\hline & & $\begin{array}{l}\text { Implementation of hygiene } \\
\text { requirements for auditing } \\
\text { and hygienic practice }\end{array}$ & 0.317 & 0.111 & 3 \\
\hline & & $\lambda \max =3.012$ & $\mathrm{CI}=0.0004$ & $\mathrm{CR}=0.0012$ & \\
\hline \multirow[t]{4}{*}{$\begin{array}{l}\text { Crisis } \\
\text { management }\end{array}$} & $0.266^{\mathrm{b}}$ & $\begin{array}{l}\text { Adaptability of service } \\
\text { caused by natural hazards }\end{array}$ & 0.269 & 0.069 & 7 \\
\hline & & Transportation accident & 0.311 & 0.080 & 6 \\
\hline & & Communication with clients & 0.406 & 0.104 & 5 \\
\hline & & $\lambda \max =4.025$ & $\mathrm{CI}=0.005$ & $\mathrm{CR}=0.005$ & \\
\hline $\mathrm{CRH}=0.018$ & & & & & \\
\hline
\end{tabular}

Note: * Different superscript letters $(\mathrm{a}-\mathrm{c})$ representing a significant difference between data within the same column in decreasing order.

As shown in Table 2, second-level factors supporting the first-level factors competitive ability and logistics \& quality assurance were fairly evenly weighted within their corresponding first-level factors, as evidenced by the closeness of their local priorities in size. For instance, local priorities of their second-level factors have small ranges of $0.065(0.265-0.200)$ and $0.016(0.332-0.316)$, respectively. First-level factors information technology and crisis management, however, display much wider variability within their respective second-level factors, 0.252 and 0.137 . 


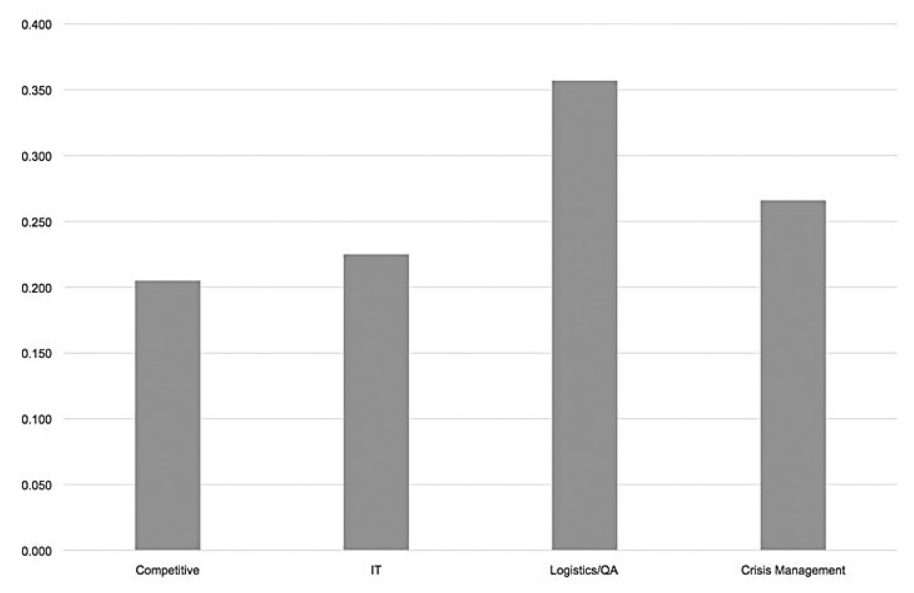

Figure 1. Local priorities of the four first-level factors

Whereas competitive ability contains the lowest global priorities, logistics and quality assurance contains the three highest ones within the entire hierarchy (see Figure 2). Although fast and convenient low-temperature logistics system is first, HACCP \&/or ISO 22000 certification and implementation of hygiene requirements of auditing; good hygiene practice follow closely and are tied for second and third, respectively. Given the criticality of getting unspoiled seafood to its destination quickly, these results are not unexpected. Among global priorities, the fourth highest priority is application of market information and accurate evaluation of market demand. This factor is not only the highest local factor within information technology but also dominates it. At 0.477 , it exceeds its next closest local priority, application of internal and external information; Internet, by 0.203 .

The fifth highest global priority, ability to communicate with customer, also dominates its first-level area crisis management, indicating that customer communication is important both in a crisis situation and under normal conditions. The remaining local factors comprising crisis management, transportation accident (sixth) and adaptability of service due to natural hazards (seventh) indicate concern for an uninterrupted supply of seafood to restaurants and hotels even during adverse conditions, extreme weather occurrences, for instance. Suppliers of seafood thus should have in place contingency plans to supply customers during such occurrences and should make this known to current and prospective customers within the Taiwanese hospitality industry as a selling point. Moreover, in such an occurrence, communication with customers is of paramount importance. 


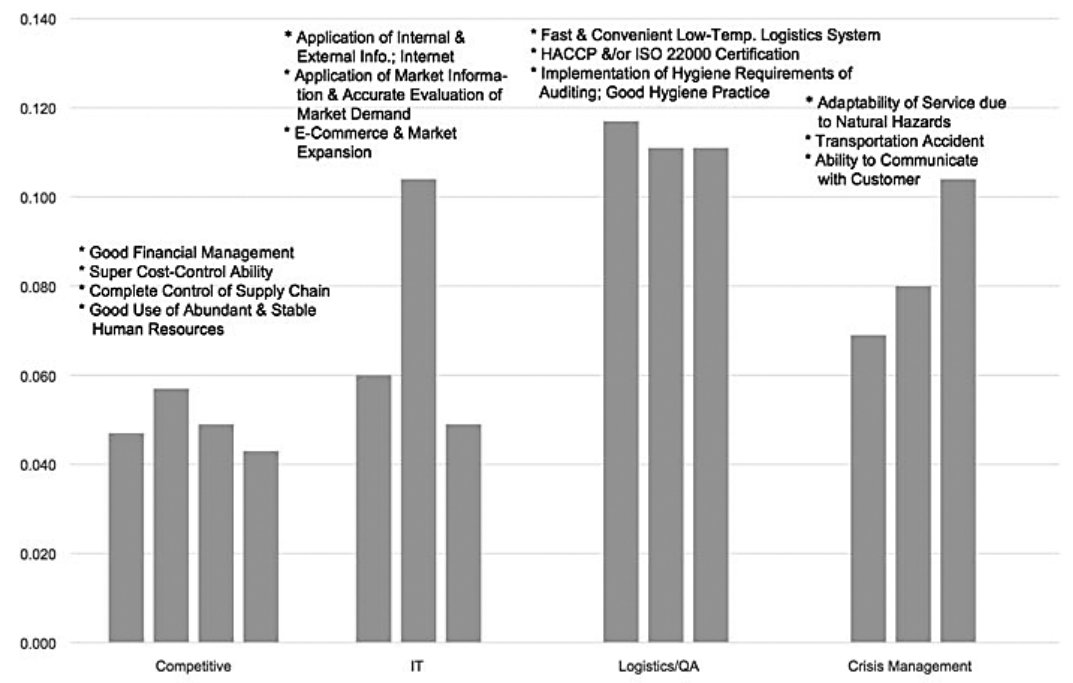

Figure 2. Global priorities of second-level factors

Note: that order of bars corresponds to order within the list above for each set of bars.

\section{CONCLUSIONS}

Organizational success has been linked to implementation of an effective process for the selection of suppliers, typically based on value-added characteristics of suppliers' products and services to a greater extent than on their pricing policies (Batt and Morooka 2003; Bradford et al. 2009; Kar and Pani 2014). Unlike those focusing on the suppliers' products and services in the manufacturing setting, the present study focused its investigation on other firm attributes such as logistics and quality assurance, crisis management, information technology, and competitive capability.

The present study has achieved certain findings by ranking two levels of factors. Among first-level factors, logistics and quality assurance was ranked highest, followed by crisis management, information technology, and competitive ability in descending order. The global (i.e., second-level) factors emphasized the importance of logistics and quality assurance; it comprised the first, second, and third global factors concerning a fast, dependable low-temperature logistics system, adherence to hygienic protocols (i.e., HACCP or ISO 22000), and other policies related to hygiene, respectively. Given seafood's perishability and the consequences to a restaurant or hotel of serving spoiled seafood to its customers, 
this concern for safe and controlled temperature transport is not surprising. Thus, this first-level factor and the second-level factors which comprise it are in accord. Similarly, the second highest-priority first-level factor crisis management is comprised of the fifth, sixth, and seventh highest global-priority second-level factors, although ability to communicate dominates, emphasizing its importance, no matter the situation. The third ranked first-level factor is strongly dominated by the second level factor concerning accurately evaluating and acting upon market demand based on market information. Although ranked fourth, this factor is virtually tied on a global level with ability to communicate. Thus, a supplier seeking to attract and keep customers would do well to emphasize, in order of importance, proper and hygienic handling of seafood; contingency planning in the event of unexpected occurrences such as inclement weather, including communication with the customer; and attention and response to market conditions with respect to demand for particular products. Communication with customers is also of importance, no matter what the situation is. Competitiveness and the second-level factors comprising it, although important, were last on the local and global levels.

Viewed as an application of supplier selection methodology within a service industry, the present study offers valuable managerial implications. Although, this process has proven itself an essential aspect of management in the manufacturing setting, it has also now been proven to be valuable and contributive to effective operations in a service setting such as hospitality industry. Moreover, the research described herein could be extended. Since procurement from suppliers comprises a significant percentage of a product's costs, other vendor capabilities could be compared and determined with respect to their relative strengths and weaknesses. As a result of the increasing intensity of competition worldwide, firms are exposed to a variety of resource constraints, such as capital, capacity, technology, and human resources. In this regard, given resource constraints, an optimum process in supplier selection must lie in the search of the best supplier to further the firm's interests. Thus, supplier selection criteria other than price, delivery, and quality could be identified depending upon the specific needs of the firm to advance its business. It is also able to assist service managers to proceed the evaluation of the supply chain in a different way as opposed to the traditional management of service level agreements. Moreover, this performance measurement model will be helpful to provide opportunities to researchers and practitioners for improvements in the process of the service supply chain.

The present study has some limitations that offer opportunities for future research. Since the data of the present study was collected from the hospitality industry in Taiwan, the results of this study may vary with the service levels, size, and geographic locations of hospitality firms. This suggests future research 
opportunities. Thus, the use of the larger sample sizes might be especially useful in future studies. The novelty of the present study rests on the application of the AHP method for supplier selection and evaluation in the hospitality industry, where limited researches have been conducted on this subject in the industry, typically in the context of an emerging country like Taiwan. Future studies can be further extended by adding additional selection criteria, one such being environmental concerns.

\section{REFERENCES}

Batt, P.J. and Morooka, R. (2003). Perceptual differences in offer quality between Western Australian rock lobster exporters and Japanese rock lobster importers. Supply Chain Management, 8(5), 476-485.

Bradford, K.D., Crant, J.M. and Phillips, J.M. (2009). How suppliers affect trust with their customers: the role of salesperson job satisfaction and perceived customer importance. Journal of Marketing Theory and Practice, 17(4), 383-395.

Buyukozkan, G., Cifci, G. and Guleryuz, S. (2011). Strategic analysis of healthcare service quality using fuzzy AHP methodology. Expert Systems with Applications, 38(8), 9407-9424.

Chandra, C. and Kumar, S. (2000). Supply chain management in theory and practice: a passing fad or a fundamental change? Industrial Management \& Data Systems, 100(3), 100-113.

Chen, C.T., Lin., C.T. and Huang, S.F. (2006). A fuzzy approach for supplier evaluation and selection in supply chain management. International Journal of Production Economics, 102, 289-301.

Chin, K.S., Pun, K.F. and Chan, J.S.F. (2002). An AHP based study of critical factors for TQM implementation in Shanghai manufacturing industries. Technovation, 22, 707-715.

Cho, D.W., Lee, Y.H., Ahn, S.H. and Hwang, M.K. (2012). A framework for measuring the performance of service supply chain management. Computers \& Industrial Engineering, 62, 801-818.

Crowe, T.J., Noble, S.J. and Machimada, S.J. (1998). Multi-attribute analysis of ISO 9001 registration using AHP. International Journal of Quality and Reliability Management, 15(2), 205-222.

Fantazy, K.A., Kumar, V. and Kumar, U. (2010). Supply management practices and performance in the Canadian hospitality industry. International Journal of Hospitality Management, 29(4), 685-693.

Feng, B., Fan, Z.P. and Li, Y. (2011). A decision method for supplier selection in multiservice outsourcing. International Journal of Production Economics, 132(2), 240-250.

Isaai, M.T., Kanani, A., Tootoonchi, M. and Afzali, H.R. (2011). Intelligent timetable evaluation using fuzzy AHP. Expert Systems with Applications, 38(4), 3718-3723.

Kahraman, C., Cebeci, U. and Ulukan, Z. (2003). Multi-criteria supplier selection using fuzzy AHP. Logistics Information Management, 16(6), 382-394.

Kar, A.K. and Pani, A.K. (2014). Exploring the importance of different supplier selection criteria. Management Research Review, 37(1), 89-105.

Kim, S.H. and Ellegaard, C. (2011). Supplier evaluation processes: The shaping and reshaping of supplier performance. International Journal of Operations \& Production Management, 31(8), 888-910.

Li, G.D., Yamaguchi, D. and Nagai, M. (2007). A grey-based decision-making approach to the supplier selection problem. Mathematical and Computer Modelling, 46(3-4), 573-581. 
Li, C.C., Fun, Y.P. and Huang, J.S. (1997). A new measure for supplier performance evaluation. IIE Transactions, 29(1), 753-758.

Maggie, C.Y.T. and Tummala, V.M.R. (2001). An application of the AHP in vendor selection of a telecommunications system. Omega, 9, 171-182.

Ng, W.L. (2008). An efficient and simple model for multiple criteria supplier selection problem. European Journal of Operational Research, 186, 1059-1067.

Pullman, M. and Rodgers, S. (2010). Capacity management for hospitality and tourism: a review of current approaches. International Journal of Hospitality Management, 29(1), 177-187.

Saaty, T.L. (1980). The Analytic Hierarchy Process: Planning, Priority Setting. New York: McGrawHill International Book.

Saen, R.F. (2009). A new approach for selecting slightly non-homogeneous vendors. Journal of Advances in Management Research, (2), 144-153.

Sevkli, M., Koh, S.C.L., Zaim, S., Demirbag, M. and Tatoglu, E. (2008). Hybrid analytical hierarchy process model for supplier selection. Industrial Management \& Data Systems, 108(1), 122-142.

Shi, X. and Liao, Z. (2013). Managing supply chain relationships in the hospitality services: An empirical study of hotels and restaurants. International Journal of Hospitality Management, 35, $112-121$.

Smith, S.L.J. and Xiao, H. (2008). Culinary tourism supply chains: a preliminary examination. Journal of Travel Research, 46(3), 289-299.

Spekman, E.R., Kamauff, J.W. Jr. and Myhr, N. (1998). An empirical investigation into supply chain management: a perspective on partnerships. Supply Chain Management: An International Journal, 3(2), 53-67.

Taliba, F., Rahmanb, Z. and Qureshic, M.N. (2011). Prioritising the practices of total quality management: An analytic hierarchy process analysis for the service industries. Total Quality Management, 22(12), 1331-1351.

Vaidya, O.S. and Kumar, S. (2006). Analytic hierarchy process: An overview of applications. European Journal of Operational Research, 169(1), 1-29.

Zhang, H.Q., Ren, L., Shen, H. and Xiao, Q. (2013). What contributes to the success of Home Inns in China? International Journal of Hospitality Management, 33, 425-434. 